\title{
Prática e performance inicial de Minuetos de Haydn por pianistas: efeitos da privação de estímulos na retroalimentação sensorial em diferentes condições de estudo
}

\begin{abstract}
Initial practice and performance of Haydn's Minuets by pianists: the effects of the deprivation of stimulus in sensorial feedback in different conditions of study
\end{abstract}

Michele Rosita Mantovani ${ }^{1}$

Regina Antunes Teixeira dos Santos ${ }^{2}$

\footnotetext{
${ }^{1}$ Universidade Federal do Rio Grande do Sul, Instituto de Artes, Porto Alegre, Rio Grande do Sul, Brasil. mantovani.michele@gmail.com

${ }^{2}$ Universidade Federal do Rio Grande do Sul, Instituto de Artes, Porto Alegre, Rio Grande do Sul, Brasil. regina.teixeira@ufrgs.br
}

\section{Resumo:}

O presente estudo teve como objetivo investigar os efeitos da privação de estímulos (aurais, visuais e cinestésicos) na retroalimentação sensorial durante a preparação inicial de peças para piano por estudantes de diferentes níveis acadêmicos. Estudantes de música $(\mathrm{N}=12)$ da graduação (iniciantes, meio e final de curso) e de pós-graduação (iniciantes de mestrado e um doutorando em final de curso), seguindo um delineamento experimental tipo hierárquico foram submetidos a quatro condições de estudo: (i) Condição A: Decodificação Visual com retroalimentação cinestésica e privação de estímulo auditivo; (ii) Condição B: Decodificação Visual com a privação de estímulo aural e cinestésico (prática mental); (iii) Condição C: Decodificação Aural com retroalimentação cinestésica e privação de estímulo visual da partitura ("tocar a música de ouvido"); Condição D: Decodificação Aural sem retroalimentação cinestésica com a privação de estímulos visual e cinestésico. Os dados obtidos foram analisados quantitativamente e qualitativamente acerca do tempo de prática despendido na realização das tarefas, das estratégias 
desenvolvidas e dos produtos atingidos pelos participantes em função das condições de estudos propostas. Os resultados revelaram efeito potencial dos níveis acadêmicos sobre o tempo despendido durante a prática nas condições $\mathrm{A}, \mathrm{C}$ e $\mathrm{D}$, bem como na compreensão musical dos participantes e na qualidade dos registros das performances (produtos) atingidos nas condições A e B. Em termos de estratégias e performances, as condições C e D deram-nos indícios de que a realização destas tarefas parece depender mais de competências acumuladas de cada estudante do que do nível acadêmico os quais estes se inserem.

Palavras-chave: Retroalimentação sensorial; prática instrumental; níveis acadêmicos, privação de estímulos sensoriais.

\section{Abstract:}

The present study aimed at investigating the effect of stimulus deprivation (aural, visual and kinesthetic) in the sensorial feedback during the initial approach to piano pieces by students belonging to different academic levels. Undergraduate (junior, sophomore and senior) and graduate music student (initial students of master's degree and one student of final doctoral degree) $(\mathrm{N}=12)$, according to a nested experimental design, were submitted to four conditions of study: (i) Condition A: Visual decoding with kinesthetic feedback and privation of aural stimulus; (ii) Condition B: Visual decoding with privation of aural and kinesthetic stimulus (mental practice); (iii) Condition C: Aural decoding with kinesthetic feedback and deprivation of visual stimulus of the score (playing by ear); (iv) Condition D: Aural decoding without kinesthetic feedback with deprivation of visual and kinesthetic stimulus. Data were analyzed quantitatively and qualitatively in terms of time of practice spent for accomplishing the tasks, developed strategies and reached products, according to each condition of study. The results revealed the potential effect of the academic level on the time spent in practice for conditions A, C and D, as well as in the musical understanding and in the quality of attained performance takes (products), for conditions $\mathrm{A}$ and B. In terms of strategies and performances, data from conditions C and D suggested the performance under such conditions seem to depend on the cumulative competences of the student rather on the academic level.

Keywords: Sensorial feedback; instrumental practice; academic levels; deprivation of sensorial stimulus.

Data de recebimento: 03/11/2014

Data de aprovação final: 20/09/2015 


\section{1 - Introdução}

A realização musical é uma das tarefas mais exigentes do sistema nervoso central humano e requer a integração múltipla das modalidades visuais, aurais e cinestésicas (ALTENMÜLLER; SCHNEIDER, 2009, p.333). A ação de tocar um instrumento musical, por exemplo, engloba uma ampla gama de informações sensoriais advindas da produção sonora, das peculiaridades da notação musical, da realização de complexos movimentos motores envolvidos na execução, bem como da interação do intérprete com o instrumento e com o ambiente da performance (FINNEY; PALMER, 2003, p.52; GINSBORG, 2005, p.128; AIELLO; WILLIAMON, 2005, p.167). As modalidades sensoriais envolvidas na performance (aural, cinestésica e visual) fornecem diferentes tipos de retroalimentações sensoriais a cada ação perceptiva, as quais permitem que o cérebro manipule as informações, bem como monitore e regule a ação (GINSBORG, 2005, p.128). Isto significa que, ao mesmo tempo em que percebemos uma informação pelas modalidades, obtemos um retorno imediato das mesmas possibilitando-nos planejar a ação futura. Tal retorno perceptivo, acionado pelos sentidos (visuais, aurais, tácteis e/ou cinestésicos) podem sofrer impasses em relação à compreensão e à realização musical nas situações de presença ou ausência de estímulos sonoros (performance privada do som do instrumento), visuais (ausência da partitura, quando a obra está em fase inicial de estudo e/ou ainda não está memorizada), táctil/cinestésico (privação ação e realização no instrumento). Para GINSBORG (2005, p.128), as retroalimentações sensoriais desses estímulos são essenciais tanto para a representação mental da música, como para produzir e monitorar os objetivos pré-determinados da performance.

Na literatura da Psicologia da Música, vários trabalhos têm investigado a função das retroalimentações sensoriais na prática e na performance. Por exemplo, BANTON (1995, p.3-16) analisou a importância das retroalimentações (visual e auditiva) na leitura à primeira vista por pianistas. A ausência da retroalimentação auditiva não alterou a performance em comparação com as condições normais de retroalimentações sensoriais, embora a ausência da retroalimentação visual do teclado prejudicasse a performance causando uma quantidade significativa de erros. FINNEY (1997, p.153-174) investigou os efeitos de eliminar ou alterar a retroalimentação auditiva na performance pianística. A retroalimentação com atraso auditivo resultou em uma quantidade maior de erros na performance que a retroalimentação com alturas alteradas, enquanto que a 
ausência de retroalimentação auditiva não afetou a performance. REPP (1999, p.409-438), ao privar a retroalimentação auditiva, averiguou alterações nos aspectos expressivos. Em geral, a privação da retroalimentação auditiva não alterou os aspectos expressivos (como o timing e a intensidade) da performance dos pianistas em relação à performance com a retroalimentação aural reagregada. FINNEY e PALMER (2003, p.51-64) pesquisaram os efeitos da retroalimentação auditiva no aprendizado e memorização de uma obra musical: esta era manipulada (presente, ausente e alterada), enquanto alguns pianistas liam uma determinada obra, e posteriormente, após a obra estar aprendida, tocavam a mesma obra de memória, com a retroalimentação auditiva. Os resultados indicaram que a retroalimentação auditiva é prioritariamente necessária no aprendizado de uma obra mais do que no contexto pós-memorização da mesma. HIGHBEN e PALMER (2004, p.1-8) investigaram se a ausência das retroalimentações cinestésicas e auditivas durante a prática ao piano afetavam a memória musical. Após algumas seções de prática de uma determinada obra musical com as retroalimentações auditiva e cinestésica, os pianistas foram instruídos a estudar sem as retroalimentações até a memorização da obra. Os resultados apontaram que não houve diferenças significativas entre o número de notas memorizadas. WÖLLNER e WILLIAMON (2007, p.39-54) analisaram o quanto as retroalimentações sensoriais (visual, auditiva e cinestésica) poderiam interferir na imagem mental da obra, especificamente na estabilidade do timing e da intensidade (dinâmica) da performance. O timing e a intensidade não apresentaram alterações significativas na ausência da retroalimentação visual e auditiva.

As retroalimentações sensoriais na prática e na performance fazem parte da aprendizagem musical. Aprendizagem musical, do ponto de vista psicológico, envolve o processamento da memória. Modelos e pesquisas da psicologia da memória têm-se preocupado em esboçar esse fenômeno em termos de decodificação, armazenamento e recuperação. Segundo GINSBORG (2005, p.124), o armazenamento sensorial consiste na recepção de estímulos extraídos do ambiente, por meio dos sentidos, ou seja, das modalidades sensoriais. Para GRUHN (2005, p.100), as informações que percebemos através dos sentidos, fazem-nos perceber e atribuir-lhes significados, de acordo com o nosso conhecimento prévio e de nossas representações mentais. Para AIELLO e WILLIAMON (2002, p.167-168), as memórias (e representações) visuais, aurais e cinestésicas estão amplamente conectadas ao conhecimento semântico musical, pois dependem da compreensão da estrutura musical, da harmonia e de outros aspectos musicais para serem formadas. Assim, nas atividades de preparação de uma dada peça no instrumento, o músico vai lidar com tipos de representações e modalidades sensoriais que vão ajudá-lo, em dependência de seu nível de expertise, a formatar o produto que esta sendo preparado. Segundo CHAFFIN, LOGAN e BEGOSH (2009, p.355), a 
memória motora ou cinestésica permite que ações sejam executadas automaticamente a partir da retroalimentação sensorial das articulações, músculos e receptores sensíveis ao toque. Os músicos se referem a este tipo de memória como ter a música "nas mãos”, um conhecimento implícito que, para ser acessado, precisa da execução física ao instrumento. A memória visual funciona como uma espécie de memória "fotográfica", referente à lembrança da partitura, como saber a localização exata de uma determinada passagem na página, tanto quanto à lembrança da postura corporal no instrumento (como as mãos sobre o teclado), como em forma de uma representação espacial (GINSBORG, 2005, p.13). Para CHAFFIN, LOGAN e BEGOSH (2009, p.355), a memória auditiva permite que as pessoas “escutem” melodias em suas cabeças independentemente das outras modalidades sensoriais. Na construção de uma performance musical, a memória auditiva auxilia o instrumentista a imaginar e criar referências sonoras no direcionamento das linhas, assim como nas intenções de expressão.

Uma abordagem empregada por pesquisadores acerca da memória em música diz respeito às restrições de retroalimentação aural, visual e/ou cinestésica. Ao nosso conhecimento, inexiste na literatura a descrição do efeito da privação de estímulos que possibilitem e/ou dificultem acionar retroalimentações sensoriais na abordagem inicial de uma peça musical. Dessa forma, o presente manuscrito relata os efeitos da privação de estímulos (aurais, visuais e cinestésicos) na retroalimentação sensorial durante a abordagem inicial de peças para piano por estudantes de diferentes níveis acadêmicos. Para tal foi analisado o tempo da prática despendido na realização das tarefas, bem como as estratégias desenvolvidas e os produtos atingidos pelos participantes em função das condições de estudos com privação de estímulos nas retroalimentações sensoriais e dos níveis acadêmicos em questão.

\section{2 - Método}

Uma amostra de 12 voluntários, estudantes de piano com média de idade de 22,58 $\pm 3,42$ e de instrução formal de 9,91 anos, participaram deste estudo. O delineamento experimental adotado foi do tipo hierárquico (nested design) e levou em conta dois fatores: (1) quatro condições de estudo, a saber: Condição A: Decodificação Visual com retroalimentação cinestésica e privação de estímulos auditivos; Condição B: Decodificação Visual com a privação de estímulo aural e 
cinestésico (também denominado de prática mental); Condição C: Decodificação Aural com retroalimentação cinestésica e privação do estímulo visual da partitura, ou seja, "tocar a música de ouvido"; Condição D: Decodificação Aural sem retroalimentação cinestésica com a privação de estímulos visual e cinestésico, isto é, sem ler a partitura e sem tocar. (2) Quatro níveis de desenvolvimento acadêmico: (i) Início de curso ( $1^{\circ}$ a $3^{\circ}$ semestre da graduação), codificados como I1, I2 e I3; (ii) Meio de curso ( $4^{\circ}$ a $6^{\circ}$ semestre), M4, M5 e M6; (iii) Fim de curso ( $7^{\circ}$ e $8^{\circ}$ semestre), F7, F8 e F9; (iv) Pós-Graduação (PG), participantes cursando mestrado e/ou doutorado, PG10, PG11 e PG12. A Figura 1 ilustra a distribuição dos participantes ao longo do delineamento.

O estímulo foi constituído de quatro minuetos extraídos de movimentos de sonatas para piano de Haydn, com de cerca no máximo 24 compassos e numerados de 1 a 4 . Como medida randômica e equilíbrio de variáveis, os fatores foram distribuídos em um quadrado latino realizado em triplicata, considerando a distribuição da ordem das tarefas nas condições de estudos, peças e níveis acadêmicos. A Figura 2 ilustra o resultado desse delineamento, no qual cada célula do quadrado latino corresponde a uma situação de coleta, seguindo a ordem de colunas verticais.

Fator 1: condições de estudo

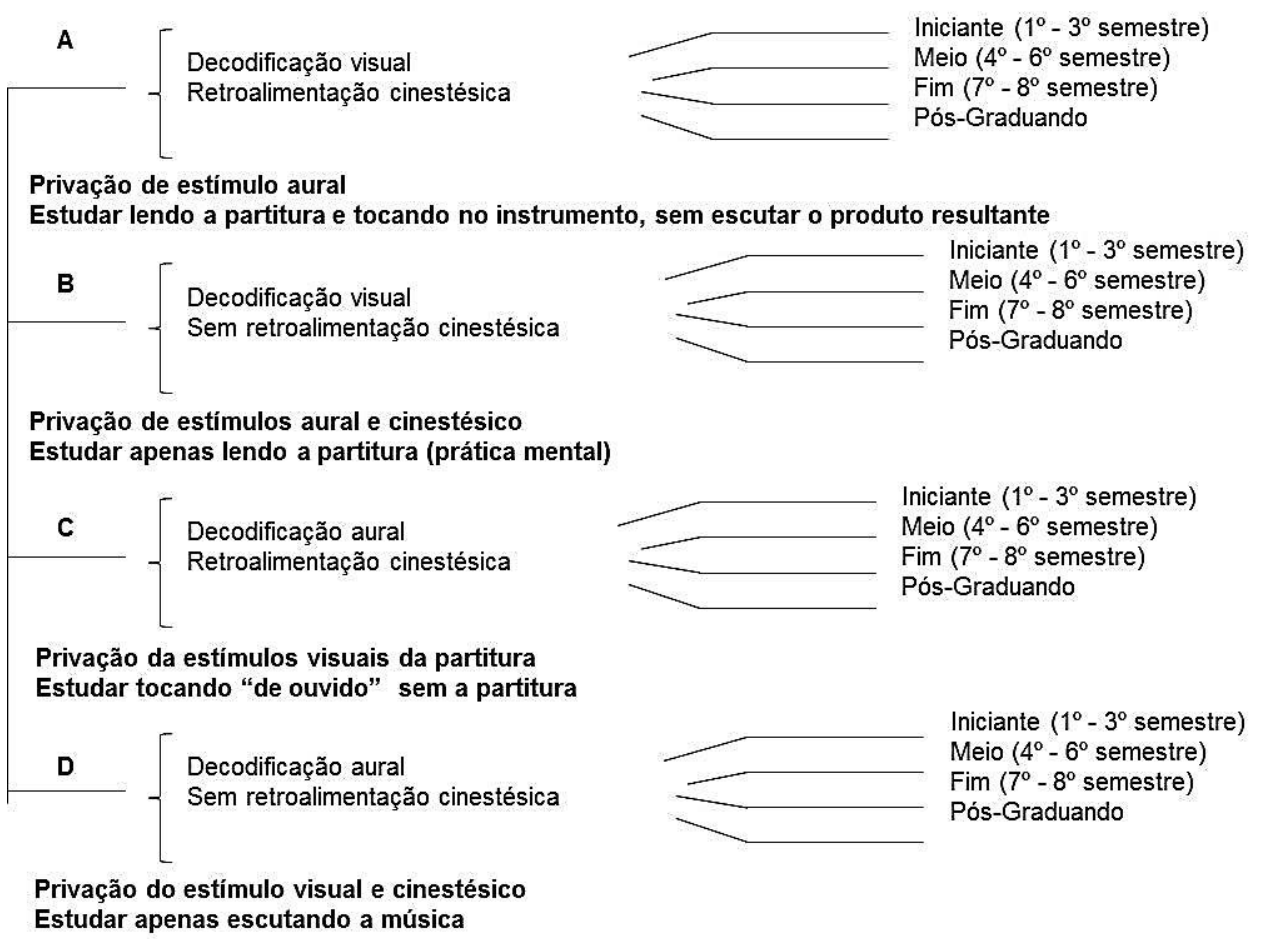$$
\text { iante }\left(1^{\circ}-3^{\circ} \text { semestre }\right)
$$

sultante

Fator 2: níveis acadêmicos 


\begin{tabular}{|c|c|c|c|}
\hline Início & Pós & Fim & Meio \\
\hline Condição A & Condição A & Condição A & Condição A \\
\hline Peça 1 & Peça 2 & Рeça 3 & Peça 4 \\
\hline Meio & Início & Pós & Fim \\
\hline Condição B & Condição B & Condição B & Condição B \\
\hline Peça 1 & Peça 2 & Рeça 3 & Peça 4 \\
\hline Fim & Meio & Início & Pós \\
\hline Condição C & Condição C & Condição C & Condição C \\
\hline Peça 1 & Peça 2 & Peça 3 & Peça 4 \\
\hline Pós & Fim & Meio & Início \\
\hline Condição D & Condição D & Condição D & Condição D \\
\hline Peça 1 & Peça 2 & Рeça 3 & Peça 4 \\
\hline
\end{tabular}

Figura 2: Condições de coleta empregadas pelos quatro níveis acadêmicos (início, meio, fim, pós-graduando) em cada conjunto de dados, segundo distribuição em Quadrado Latino. As peças 1-4 referem-se aos estímulos.

Nas condições de estudo, cada participante ficou só em uma sala e pode estudar a peça estipulada por tempo indeterminado, até se sentir satisfeito(a) e/ou considerar a peça como estudada. As técnicas de coleta de dados foram: (a) registro da performance da peça (com as retroalimentações reintegradas, isto é, na condição habitual de performance: tocando, escutando, com ou sem a partitura, dependendo da condição preestabelecida); (b) entrevista semiestruturada cujo roteiro contemplou questões que visavam compreender as impressões pessoais dos participantes acerca desta experiência, bem como as estratégias desenvolvidas, o foco de atenção e tipo de fonte perceptiva recorrida.

Cada participante realizou quatro encontros para o experimento, que geraram quatro performances gravadas. Cada condição gerou uma performance e uma entrevista semiestruturada para cada participante, o que totalizou um conjunto de 48 performances e 48 entrevistas. As performances foram analisadas em termos de (i) Foco de atenção e (ii) retroalimentação perceptiva sobre os eventos. Os parâmetros referentes ao Foco de atenção foram elencados a partir de uma análise preliminar das entrevistas, onde foi levada em conta a incidência dos aspectos salientados pelos participantes. Com relação aos parâmetros relativos à retroalimentação perceptiva sobre os eventos, a escolha foi balizada pela temática de modalidades sensoriais pertinente à questão investigada. A Figura 3 descreve os aspectos abordados no quesito Foco de atenção sobre os eventos. 


\begin{tabular}{|c|c|}
\hline Parâmetros & Aspectos considerados \\
\hline Notas/intervalos & $\begin{array}{l}\text { Relação nota-a-nota/intervalar, saltos, [imaginação/suposição do] nome } \\
\text { da nota. }\end{array}$ \\
\hline Ritmo & Compasso, duração, pulso, métrica, andamento, timing, agógica \\
\hline Melodia & $\begin{array}{l}\text { Melodia, desenho melódico, contorno, linha/voz da mão direita } \\
\text { (soprano). }\end{array}$ \\
\hline Harmonia & $\begin{array}{l}\text { Tonalidade/escala/armadura da clave, acordes, funções, movimento ou } \\
\text { progressões harmônicas, modulação, cadências, linha/voz da mão } \\
\text { esquerda (baixo)/acompanhamento. }\end{array}$ \\
\hline $\begin{array}{l}\text { Segmentação/organização das } \\
\text { partes }\end{array}$ & Frase, partes, seção, relação (agrupamento) entre as partes. \\
\hline Expressão & $\begin{array}{l}\text { Sonoridade, dinâmica, articulação/diferenças de toque, timing, gesto } \\
\text { musical, arco/contorno da frase, intenção de cantar/fazer musical, } \\
\text { equilíbrio sonoro, recursos tímbricos. }\end{array}$ \\
\hline Mecânica & $\begin{array}{l}\text { Pedal, mão direita/esquerda/mãos juntas, posição das mãos, topografia } \\
\text { do teclado, dedilhado, distância, trinados, ornamentos, adaptação ao } \\
\text { piano. }\end{array}$ \\
\hline Estilo & $\begin{array}{l}\text { Natureza da articulação, qualidades estilísticas (minueto/período } \\
\text { clássico), interpretação da quadratura clássica. }\end{array}$ \\
\hline
\end{tabular}

Figura 3: Foco de atenção sobre os eventos: descrição dos parâmetros de análise e aspectos considerados.

A Figura 4 descreve os aspectos abordados no quesito Retroalimentação perceptiva sobre os eventos.

\begin{tabular}{|c|c|}
\hline Parâmetros & Aspectos considerados \\
\hline Fonte imaginária/mental & $\begin{array}{l}\text { Escuta mental, imaginação da melodia/harmonia/baixo, imaginação do } \\
\text { som, imaginação metafórica, imaginação do teclado, imaginação do } \\
\text { movimento/da performance, lembrança do que memorizou/reteve. }\end{array}$ \\
\hline Fonte cinestésica & $\begin{array}{l}\text { Movimento/gesto da mão direita/esquerda, de mãos juntas, movimento do } \\
\text { pedal, movimento de distâncias, sensação de dedilhado, execução na } \\
\text { mesa/no ar/sobre o teclado/na perna, regência. }\end{array}$ \\
\hline Fonte oral/aural & Solfejo em voz alta, canto da melodia/do baixo. \\
\hline Fonte auditiva & Escuta da qualidade da própria performance/do áudio, imitação do áudio. \\
\hline Fonte visual & Partitura, visualização do teclado, identificação de padrões. \\
\hline Fonte transcrita & Qualquer código escrito (cifra, notas, ritmo, etc.). \\
\hline
\end{tabular}

Figura 4: Retroalimentação perceptiva sobre os eventos: descrição dos parâmetros de análise e aspectos musicais considerados. 
Como procedimento analítico, a cada produto de performance, em cada uma das quatro condições de estudo ( $\mathrm{N}=48$ produtos de performance), foi atribuído graus de 1 a 5 (Escala de Likert) para cada um dos parâmetros supracitados com base nas entrevistas e performances, e utilizados no tratamento estatístico. Os critérios da escala de Likert foram:

1. Ausente ou impreciso (não fala, nem faz);

2. Percepção pouco suficiente do parâmetro (fala, mas não faz);

3. Compreensão/necessidade emergente das possibilidades do parâmetro (fala, mas faz com pouca convicção);

4. Manipulação do parâmetro (fala e faz);

5. Domínio e/ou ajuste do parâmetro (não fala, mas faz bem ou fala e faz bem).

Primeiramente, essa atribuição foi realizada independentemente por dois árbitros, que numa segunda etapa, foi confrontada por ambos de forma a atingir um consenso para cada uma das atribuições. A análise estatística foi realizada com o software SPSS®.

\section{3 - Resultados e Discussões}

\section{1 - Análise do tempo de prática}

O tempo despendido na realização das tarefas pode funcionar como um indício tanto do grau de facilidade/dificuldade enfrentado pelo participante em uma dada condição de estudo, assim como de seu grau de expertise. Estima-se que tarefas mais difíceis ou níveis mais elementares de expertise (iniciante, por exemplo) possam exigir mais tempo em sua execução. Não se pode negligenciar que esse tempo despendido pode ser afetado por aspectos tais como nível de concentração e engajamento dos participantes, bem como a qualidade almejada do produto a ser atingido em cada condição. Dessa forma, a variável tempo foi analisada sob dois aspectos interrelacionados: a natureza da condição de estudo e o nível acadêmico. A Figura 5 apresenta o tempo gasto pelos participantes dispostos em cada condição de estudo.

A Figura 5 aponta que as condições A e B foram aquelas em que foi despendido o menor tempo de prática entre todos os níveis acadêmicos. Em ambas as condições (A e B), o tempo de preparação dos estudantes foi bastante similar, haja vista a mediana de 12 e 10 min resultante em 
cada condição, respectivamente (observada no detalhe dos diagramas de caixa da Figura 5 (a e b)). Na condição A, dez dos doze participantes realizaram o estudo em média de 11,90 \pm 5,76 min e mediana de 12 min. Dois participantes de início de curso levaram um tempo significativamente superior em comparação com os demais níveis, apesar de considerarem a tarefa fácil, configurando-se como observações extremas (outliers), conforme ilustração do diagrama de caixa correspondente. Na condição A, pode-se observar uma tendência de diminuição do tempo gasto para realização do estudo à medida que se desloca dos participantes de início aos de fim de curso (indicada pela curva tracejada). Esse comportamento sugere um potencial efeito do nível acadêmico nessa condição de estudo. O tempo médio dos participantes de pós-graduação foi maior que a média dos participantes de meio e fim de curso. Nesse caso, não se pode negligenciar que os participantes de pós-graduação dispõem de um nível de proficiência mais diferenciado que lhes possibilitam a perseguir um nível qualitativamente diferenciado de realização, e isto pode ter ocasionado um tempo maior de estudo.
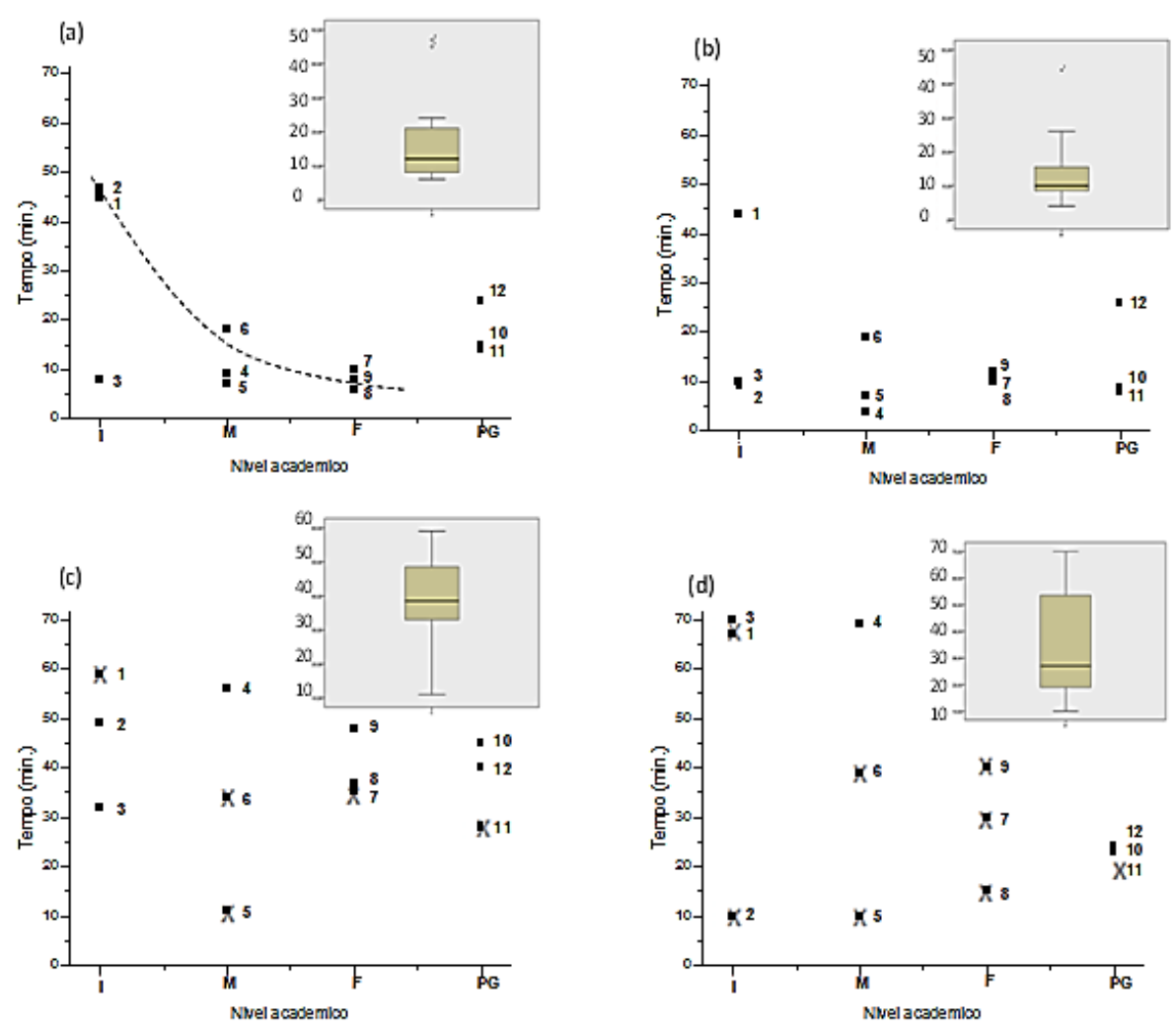

Figura 5: Efeito do nível acadêmico no tempo despendido na prática em cada condição de estudo: (a) Condição A; (b) Condição B; (c) Condição C; (d) Condição D. I = Inicio de curso; M = Meio de curso $; \mathrm{F}=$ Fim de curso $;$ PG = Pós-graduação. $\mathrm{N}=12$. 
Para a condição B (Figura 5), o nível acadêmico também não influenciou no tempo de estudo: com exceção do participante $\mathrm{I} 1$, todos os outros estudantes $(\mathrm{N}=11)$ realizaram a tarefa numa margem de tempo próxima, com média de 11,36 \6,10 min. e mediana de $10 \mathrm{~min}$. Onze participantes (inclusive o estudante I1) já haviam realizado este tipo de estudo em outras situações, em geral com uma peça já aprendida, e apenas um estudante (participante M5) disse nunca ter estudado desta forma, o que também não afetou a média de tempo de estudo nesta condição. O nível acadêmico, porém, refletiu-se na percepção sobre a tarefa: todos os estudantes de inicio e meio de curso e apenas um de pós-graduação (participante PG11) consideraram-na difícil, enquanto que os demais participantes, de fim de curso e pós-graduação, fácil.

Para as condições C e D (Figura 5), pode-se observar que a maior dispersão no tempo de estudo ocorre entre os estudantes do nível de meio de curso (media de 39,5 \pm 13,9 min, mediana 38,5 para

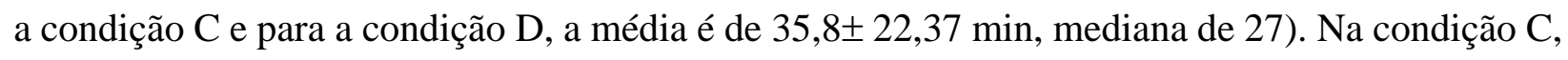
pode-se considerar que a experiência prévia com este tipo de atividade também colaborou para a homogeneidade do tempo em relação aos níveis acadêmicos: dos doze participantes, dez deles relataram que já haviam aprendido a tocar alguma música "de ouvido" (os dez participantes afirmaram ter aprendido músicas do repertório popular e apenas quatro dentre esses afirmaram ter aprendido também músicas do repertório erudito); dois participantes de meio de curso (M4 e M5), nunca haviam estudado desta forma.

Em relação à condição D, observa-se (Figura.5) que a média de tempo despendido reduziu à medida que o nível acadêmico aumentou, porém com resultados diferenciados. Cabe salientar que o tempo fora afetado pela dificuldade dos participantes em realizar a tarefa sem o instrumento e pela ênfase na transcrição da gravação por parte de todos os participantes, o que consequentemente inibiu o foco sobre a performance e levou a exaustão e desistência de 8 participantes (assinalados com um "x", na Figura 5). O relato abaixo exemplifica estas impressões:

Eu não consigo, sem o piano eu fico sem chão e aí eu bloqueio, eu não consigo
ouvir, eu tento, eu não consigo. Eu não acertei nenhum ritmo, não acertei nada. Eu
me sinto sem um pedaço mesmo. (...) eu tô frustrada, na verdade. Porque eu fiquei
pensando, "ah, tirei de ouvido com o instrumento, sem o instrumento não vai ser
tão difícill". Mas eu me senti totalmente sem referência. (Condição D, F9, p. 20)

PG10 e os demais estudantes (I2, I3, M4, F8 e PG12) foram os únicos a executarem a peça no piano num resultado bastante próximo ao da gravação. Em termos de facilidade/dificuldade na realização da condição $\mathbf{D}$, o nível acadêmico não foi fator influente: todos os participantes 
consideraram a tarefa difícil e nenhum deles relatou total satisfação com a performance, excetuando PG12 que considerou a tarefa fácil e sentiu-se satisfeito com sua performance. Todos os estudantes (exceto PG12) também relataram não terem vivenciado nenhuma experiência semelhante além da realização de ditados durante as aulas de percepção musical cursadas na graduação.

O conjunto de dados foi analisado por escalonamento multidimensional (MDS), que é um método de estatística inferencial exploratória, feito através de dados de similaridade (ou dissimilaridade) que indicam, através de medidas numéricas ou por ordenação, o quanto são próximos ou percebidos como semelhantes os objetos (estímulos) em estudo (HAIR et al., 2009, p. 482). A Figura 6 mostra o MDS resultante do tempo gasto pelo conjunto de participantes nas quatro condições. Dessa forma, de acordo com o mapa perceptual resultante, interpretou-se a abscissa como sendo o recurso de áudio e de partitura, enquanto a ordenada, como sendo o recurso de teclado. Em outras palavras, esses recursos correspondem aos canais aural e visual (abscissa) e cinestésico (ordenada). Segundo a Figura 6, a condição A encontra-se próxima da condição B (similaridade) na dimensão áudio/partitura, mas próxima da condição C, na dimensão teclado, distinguindo-se (por dissimilaridade) da condição D. Relação análoga existe entre a condição B com as condições A e D. O mapa perceptual resultante comprova a disposição do delineamento metodológico da presente pesquisa em termos de disposição (similaridade / afastamento), bem como de complementaridade de modalidades perceptivas envolvidas.

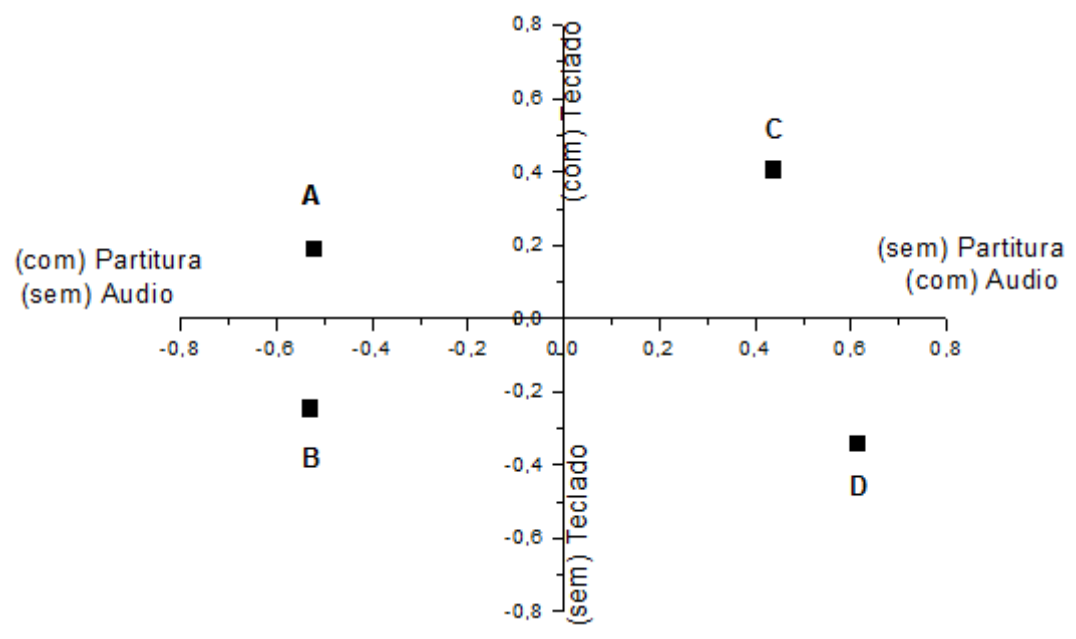

Figura 6: Mapa perceptual obtido por escalonamento multidimensional gerado a partir dos tempos despendidos nas quatro condições de estudo. 


\section{2 - Análise das estratégias}

Foram elencadas 23 estratégias, sendo apenas oito comuns entre todas as condições, a saber: (1) decodificação das partes (em relação à estrutura e forma musical), (2) foco de atenção nas notas, (3) foco de atenção na melodia, (4) foco de atenção no ritmo, (5) foco de atenção na harmonia, (6) foco de atenção nos movimentos digitais/gestuais, (7) foco de atenção nos ornamentos e (8) foco de atenção solfejo. As demais estratégias pareceram depender especificamente da tarefa proposta para suprir o(s) estímulo(s) ausente(s) e/ou atender às necessidades de cada participante perante a situação.

A condição A (Figura7) apresentou um total de 15 estratégias e a partir delas pôde-se constatar que o principal objetivo dos participantes foi atingir uma performance qualitativa, tanto em relação ao domínio dos aspectos motores e compreensão dos aspectos estruturais da música, quanto em relação ao refinamento artístico da performance. Para atingir este objetivo, os estudantes buscaram compensar a privação aural recorrendo em maior incidência às estratégias de imaginação sonora e solfejo, uma vez que, a partir destas, os músicos relataram terem construído uma representação interna da música para nortear seus processos de estudo e articular suas intenções musicais. Observa-se também que todos os níveis visaram decodificar partes, notas, melodia, harmonia e ritmo, porém, em índices variados, ou seja, houve a intenção de compreender os aspectos estruturais da música proposta. Neste âmbito, constatou-se um sutil efeito do nível acadêmico, pois se observa que os participantes de início de curso enfatizaram o aprendizado das notas, enquanto que os participantes de fim de curso e pós-graduação enfatizaram a compreensão destes aspectos em agrupamentos mais amplos como a melodia e a harmonia, por exemplo. Sobre os participantes de meio de curso, nota-se que a ênfase dada sobre estes aspectos estruturais foi mínima, pois o foco está voltado à expressão; porém, tocar com expressão parece ser uma tarefa laboriosa para esse nível de competência ao ponto de inibir o foco de atenção sobre os elementos básicos da música; assim, ler a partitura e ser expressivo são tarefas que não ocorrem simultaneamente sem que uma delas seja depreciada para este nível. Cabe aqui ressaltar que o foco nos aspectos expressivos não inibiu a atenção sobre os aspectos estruturais entre os alunos de pósgraduação, o que nos dão indícios de potencial efeito do nível acadêmico na realização desta tarefa. 


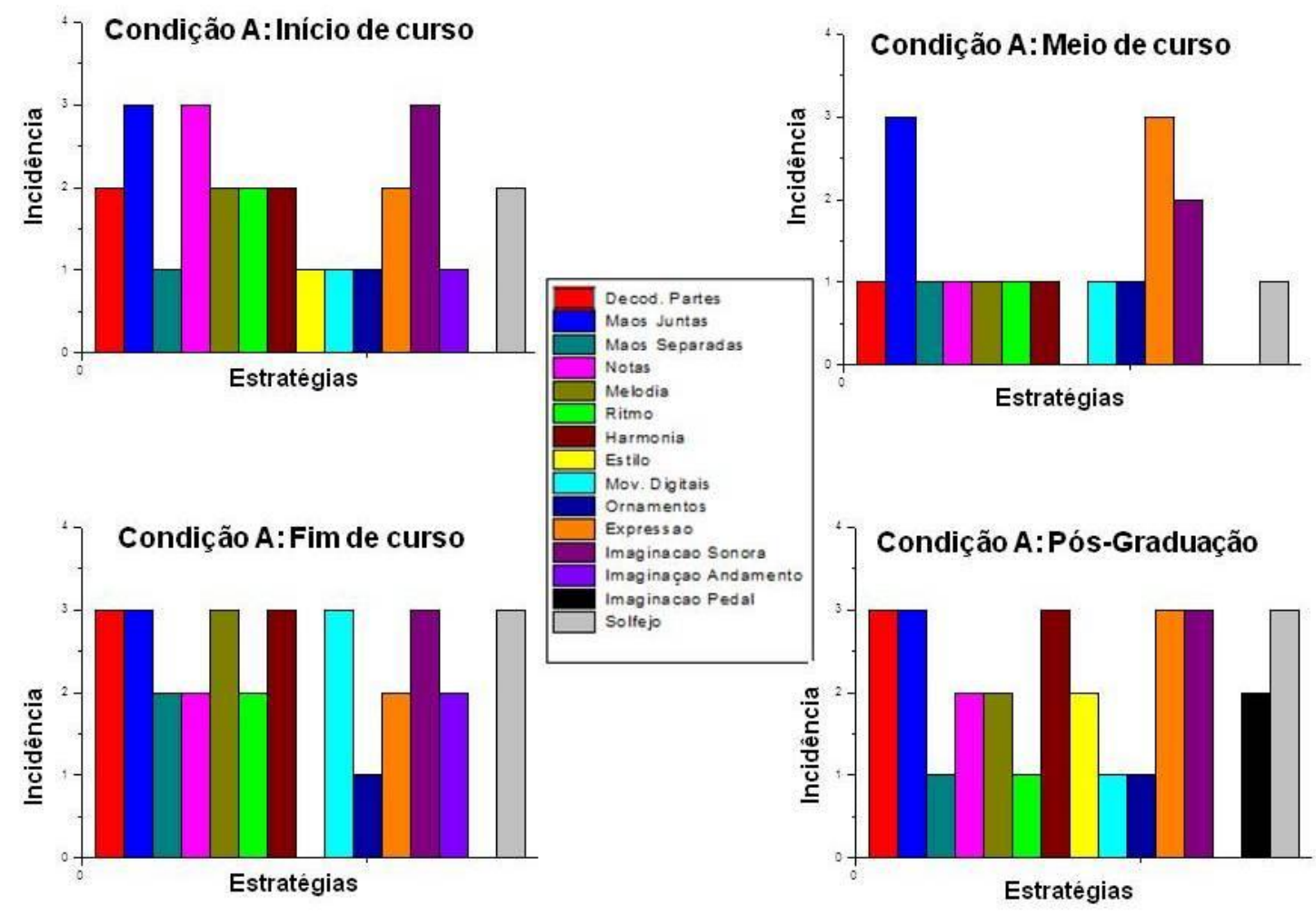

Figura 7: Distribuição e incidência das estratégias de estudo por níveis acadêmicos (Condição A): início, meio e fim de curso, e pós-graduação.

Nota-se na Figura 7 que, independentemente do nível acadêmico, houve a preocupação em coordenar aspectos motores com vistas a uma performance em nível fluente através de estratégias de estudo de mãos juntas, de mãos separadas e foco de atenção nos movimentos digitais/gestuais. O emprego das mesmas pode ser relacionado ao fato de que a maioria dos participantes apontou a segurança nos aspectos motores como foco de aprendizagem, visto que nove participantes consideraram a peça aprendida ao conseguirem tocar a peça com fluência. Embora todos os níveis tivessem evidenciado alguma intenção expressiva em suas performances, as estratégias referentes ao refinamento artístico (foco no estilo, andamento, ornamentos e pedal) apresentaram-se em menor proporção para todos os níveis na ausência de retroalimentação aural.

Na condição B foram elencadas 14 estratégias (Figura 8), e a partir delas observou-se que o foco da aprendizagem foi também a realização da performance, porém a prioridade foi compensar a privação cinestésica, mais do que compensar a privação aural, uma vez que todos os participantes realizaram movimentos fora do instrumento (tocando no ar, na perna, na mesa, na tampa do piano e também sobre o teclado sem abaixar as teclas) para estabelecer dedilhados e gestos, e as estratégias de imaginar como a música soaria e de solfejo foram menos contempladas. Neste 
escopo, outras duas estratégias foram utilizadas em menor índice para suprir a dimensão espacial do instrumento: imaginação e visualização do teclado.

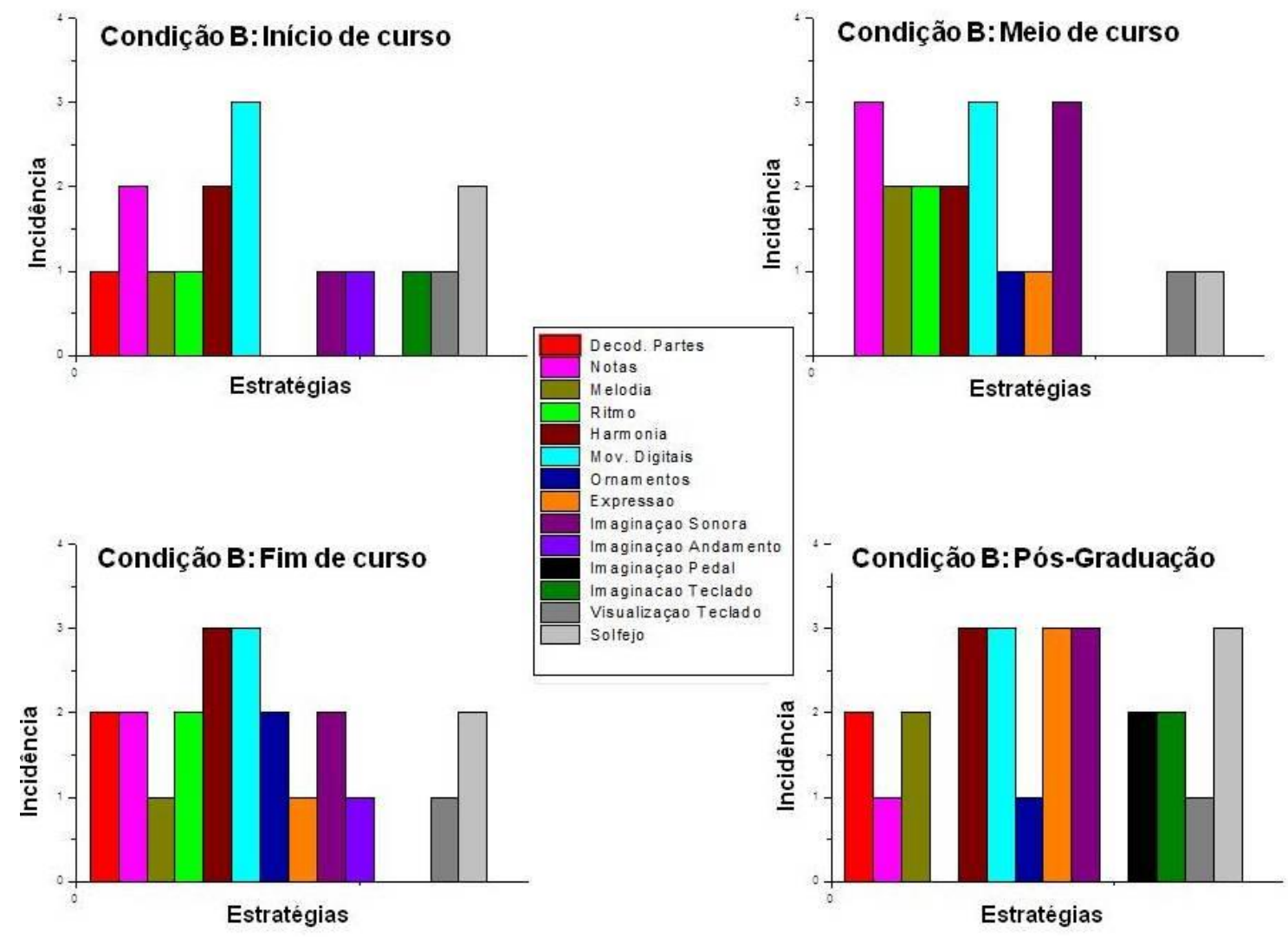

Figura 8: Distribuição e incidência das estratégias de estudo por níveis acadêmicos (Condição B): início, meio e fim de curso, e pós-graduação.

Este foco cinestésico fez com que a atenção sobre os aspectos estruturais da música (partes, notas, melodia, ritmo, harmonia) diminuísse para todos os níveis acadêmicos. Nesta discussão, pôde-se constatar um leve efeito do nível acadêmico: na condição B os participantes de início de curso tendem a minimizar o foco de atenção sobre vários aspectos estruturais; já entre os participantes de meio de curso, o foco sobre as estruturas mais amplas (melodia e harmonia) é também relativamente minimizado, e passa a ser centrado em unidades menores, neste caso, nas notas; entre os participantes de fim de curso e pós-graduação, o destaque à harmonia sugere a compreensão musical em agrupamentos maiores, embora outros aspectos estruturais também sejam menos enfatizados. Ademais, estratégias visando do refinamento artístico da performance (ornamentos, expressão, imaginação do andamento e do pedal) apresentaram menor incidência para todos os níveis acadêmicos, porém pôde-se constatar efeito do nível acadêmico acerca dos aspectos expressivos que foram mais evidenciados à medida que o nível acadêmico aumentava: 
para esta amostra investigada, conciliar expressão com a leitura da partitura e com a coordenação de movimentos parece ser uma tarefa impossível para os participantes de inicio de curso, complexa para os participantes de meio e fim de curso e mais exequível para os participantes de pósgraduação.

Na condição C foram elencadas 17 estratégias (Figura 9) e a partir delas se observou que o foco da aprendizagem evidenciado pelos participantes foi compensar a privação em questão por meio da apreensão e compreensão dos elementos estruturais do estímulo áudio, a fím de manipulá-los no instrumento, isto é, tirar a música de ouvido. Para isso, todos os níveis acadêmicos recorreram em grande incidência à melodia, à harmonia e ao ritmo, e em menor incidência, às partes e às notas.

Pode-se afirmar que os participantes recorreram prioritariamente à compreensão destas estruturas musicais para a construção de uma representação mental que permitisse subsídios básicos para sua execução no instrumento, fosse esta construída pela prática até a memorização ou pela prática com o auxílio da escrita (anotações). Nota-se ainda o uso de outras estratégias para este fim: escuta inicial completa, regência, realização simultânea com a gravação, solfejo e gravação de trechos no celular, sendo as três primeiras empregadas para auxiliar o processo de compreensão das dimensões estruturais e as duas últimas para economizar tempo e energia, reduzindo o esforço das retomadas de um dado trecho e evitando ter de sair do instrumento para manejar o equipamento de som. Assim, tendo acesso a algum tipo de representação do estímulo aural que possibilitasse a execução musical, supunha-se que os participantes buscariam, em segunda instância, algum tipo de refinamento para suas performances. Entretanto, isto não parece ter sido enfatizado nesta condição, visto que apenas duas estratégias contemplaram este aspecto: foco de atenção na expressão e nos ornamentos, realizadas por cinco participantes. Além disso, os estudantes relataram dificuldade em elaborar suas intenções interpretativas desvinculadas do modelo auditivo e/ou sem a ajuda da partitura. Também a atenção sobre os aspectos cinestésicos fora minimizada: mesmo que as estratégias de estudo de mãos separadas e mãos juntas levasse a realização de movimentos, estas contemplavam a decodificação aural dos aspectos estruturais, com vistas à compreensão das linhas atribuídas às mãos direita e esquerda, e não a estabelecer e/ou coordenar movimentos envolvidos na execução; ademais, apenas uma estratégia foi empregada para esta finalidade puramente cinestésica (foco de atenção nos movimentos digitais/gestuais), porém sem ênfase entre os participantes (empregadas por um aluno de fim de curso e dois alunos de pósgraduação). Em suma, o foco sobre as dimensões estruturais diminuiu a atenção dos participantes 
sobre os aspectos cinestésicos e expressivos, dando evidências de que o foco numa performance artisticamente qualitativa também fora fortemente minimizado. Ademais, não foram constatados efeitos dos níveis acadêmicos na realização das tarefas.
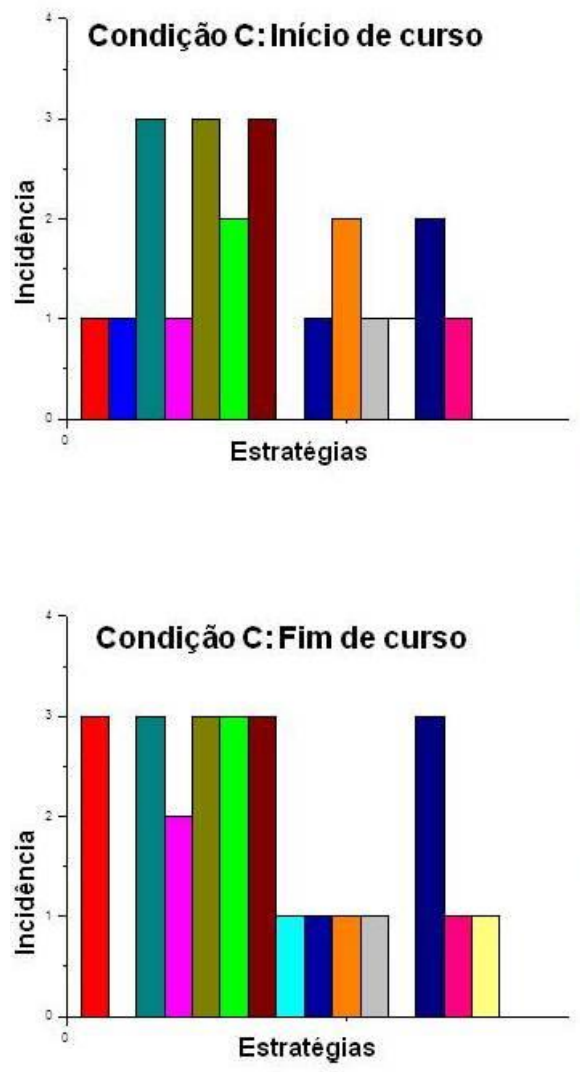

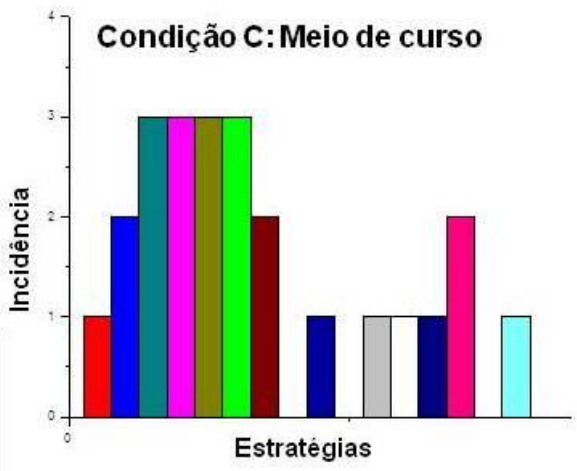
Maos Separadas Notas Melodia Ritmo Harmonia Mov. Digitais Ornamentos Expressao Solfejo EscutaCompleta Anotaçoes Memorizaçao Regencia Realiz. Simult. Grav. Celular

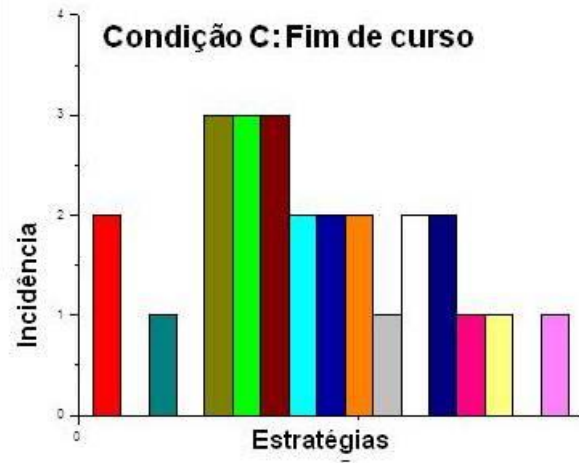

Figura 9: Distribuição e incidência das estratégias de estudo por níveis acadêmicos (Condição C): início, meio e fim de curso, e pós-graduação.

Para a condição D foram elencadas 14 estratégias (Figura 10) pelas quais se constatou que a primeira abordagem dos estudantes referiu-se à decodificação aural dos elementos estruturais presentes na gravação, com ênfase sobre a harmonia, melodia e ritmo, seguidos da decodificação das partes e notas. Entretanto, diferente da condição anterior, os estudantes não tiveram o auxílio do instrumento neste processo para tocar aquilo que ouviam, e o recurso recorrido para compensar esta privação cinestésica e a ausência da partitura foi a realização de anotações, contemplada por todos os participantes. Também a escuta inicial completa (realizada minimamente entre todos os níveis acadêmicos), a regência (realizada apenas por participantes de início e fim de curso) e o solfejo (realizado por oito participantes com destaque entre aqueles de meio de curso) foram empregados a fim de possibilitar as anotações. Com isso, se observa que o foco da aprendizagem 
passou a ser a transcrição dos aspectos estruturais, através da decodificação aural. Apenas um participante (PG10) desistiu de transcrever e demonstrou que uma execução exploratória seria possível sem o recurso do registro escrito. Para isso, PG10 utilizou a estratégia de memorização aural, escutando a peça por várias vezes até "mapeá-la" suficientemente para executá-la no instrumento. Além disso, PG10 também visualizou o instrumento e realizou movimentos digitais/gestuais para auxiliar a compreensão do estímulo aural visando à execução. Já os gráficos dos alunos de início e meio de curso apresentam uma lacuna no espaço destinado a estas estratégias, e apenas mais dois estudantes (F7 e PG11) realizaram estas estratégias com o intuito de auxiliar a transcrição, e não com vistas à execução, como fez PG10.

Ademais, os recursos de expressão foram praticamente desconsiderados entre todos os níveis acadêmicos, visto que apenas os ornamentos foram observados por dois estudantes de pósgraduação e que as estratégias empregadas para este fim nas demais condições (estilo, expressão, imaginação do andamento para determinar o caráter da peça e imaginação do pedal, por exemplo) não foram contempladas. Pôde-se ainda constatar potencial efeito do nível acadêmico, visto que a quantidade de estratégias empregadas era maior à medida que acadêmico aumentava. Por fim, as estratégias aqui evidenciadas não efetivaram o aprendizado dos participantes para esta condição, visto que oito participantes desistiram de realizar a tarefa e apenas quatro consideraram a tarefa concluída após transcreverem a gravação por completo; além disso, o objetivo de aprendizagem esperado para esta condição era a execução musical, pelo menos das ideias musicais compreendidas, e não uma transcrição propriamente dita. 


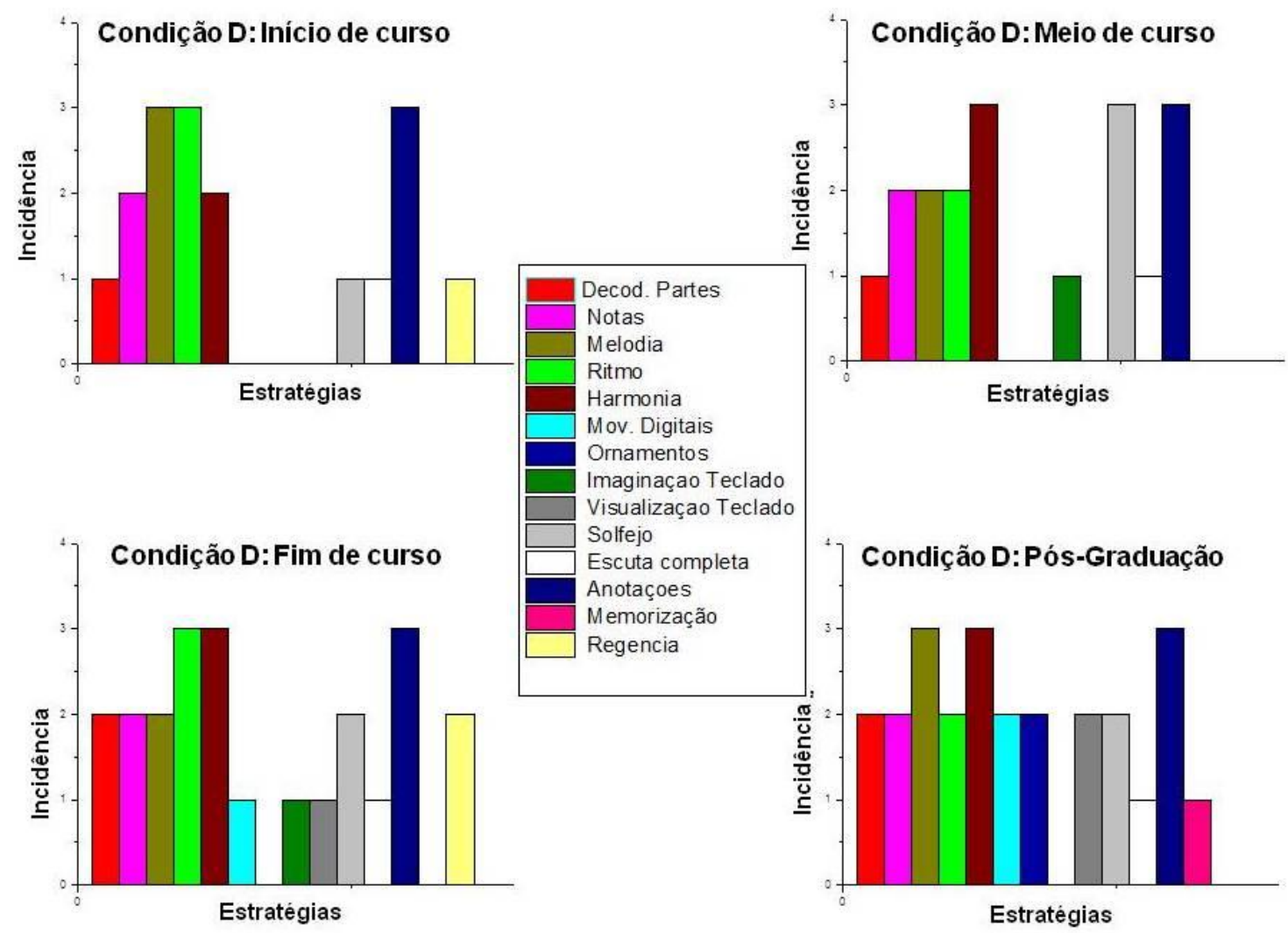

Figura 10: Distribuição e incidência das estratégias de estudo por níveis acadêmicos (Condição D): início, meio e fim de curso, e pós-graduação.

\section{3 - Análise das performances}

As performances da condição A apontam que oito participantes conseguiram tocar a peça proposta com segurança na leitura da mesma e com fluência (isto é, execução de agrupamentos rítmicos, melódicos e harmônicos corretos com manutenção de andamento coeso), enquanto que quatro (I1, M5, M6 e F7) realizaram suas performances com interrupções e erros de leitura. O dendrograma da Figura 11 apresenta a análise de clusters para esta condição, onde é visível dois grandes agrupamentos: (i) os quatro participantes (I1, M6 e F7 e M5) que tiveram problemas de leitura e (ii) o grande grupo de oito participantes que realizaram a condição A com fluência.

Com relação à condição A, a análise de cluster permitiu classificar os estudantes em grupos, mas não exclusivamente constituídos de um mesmo nível acadêmico. Apesar disso, em dois grupos pode-se observar a presença de dois participantes pertencentes a um mesmo nível acadêmico. Isso aconteceu com os níveis extremos (I2 e I3, assim como PG11 e PG12). Em termos de observação 
da performance os participantes de pós-graduação e um de fim de curso (F8) tocaram expressivamente em termos de relação corporal/gestual e resultado sonoro (F8, PG10, PG11, PG12). Os demais participantes pareceram focar-se na comunicação do entendimento elementar da partitura em termos de dimensões estruturais. Alguns estudantes tentarem ser expressivos com o corpo, como F9, entretanto o resultado sonoro foi incoerente com o gestual do participante.

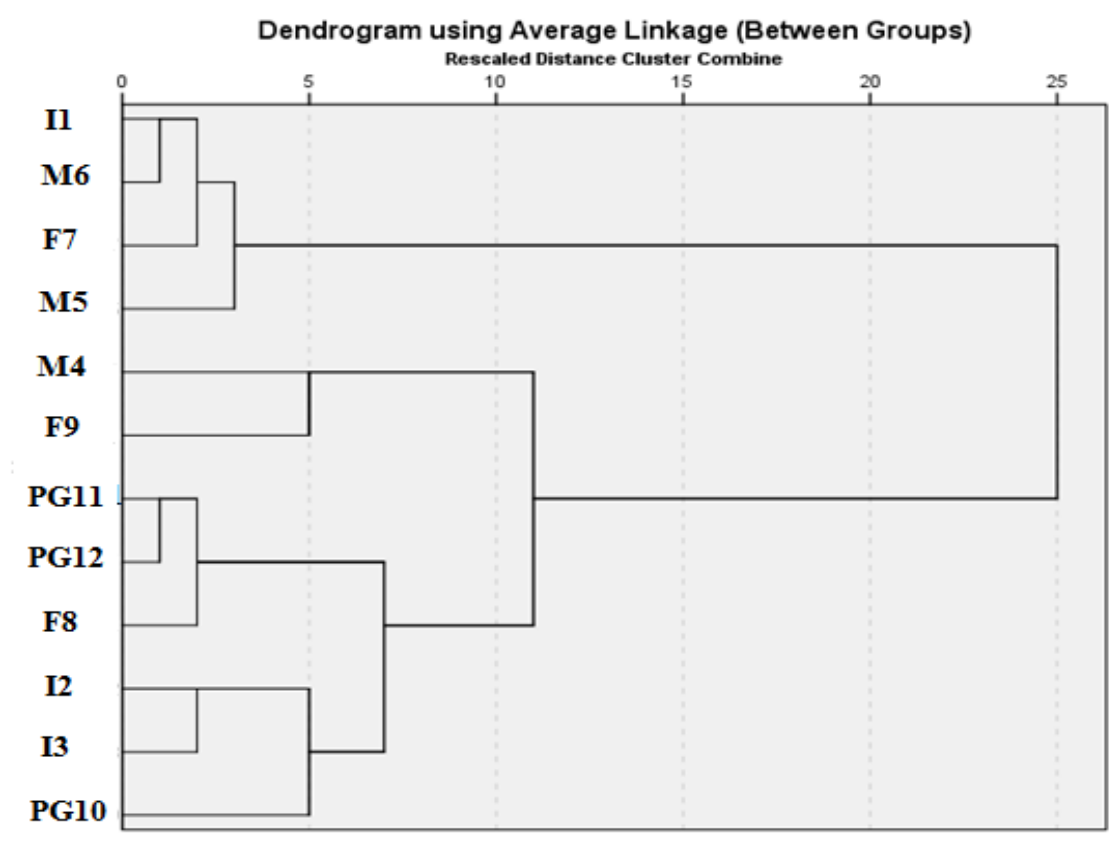

Figura 11: Dendrograma dos casos na condição A. Avaliação da performance. $N=12$.

As performances da condição B indicam que oito participantes (I1, I2, I3, M5, M6, F7, F8 e F9) tocaram de forma não fluente, dadas pelas interrupções contínuas por erros e dúvidas de leitura da peça, e em alguns casos (M5, M6 e F7) pela escolha de um andamento significativamente mais lento que o andamento das demais performances, além de terem apresentado os mesmos erros de leitura. Apenas quatro participantes (M4, PG10, PG11 e PG12) realizaram suas performances com fluência, com segurança na leitura da peça e sem interrupções. O dendrograma da Figura 12 apresenta a análise de clusters para esta condição, onde é visível, mais uma vez, dois grandes agrupamentos: (i) nove participantes correspondentes ao início, meio e fim de curso e (ii) três participantes de pós-graduação.

A análise de clusters, no caso da condição B, permitiu revelar o efeito do nível de proficiência dos participantes de pós-graduação, que se diferencia dos estudantes de graduação em termos de fluência na execução e intenção expressiva. Para os participantes em nível de graduação, as 
privações das retroalimentações aurais e cinestésicas limitaram a manipulação de aspectos de leitura da peça, segmentação/organização das partes, dinâmicas, articulações, pedal e andamento. Dentre os aspectos afetados estão a leitura da peça (oito performances), segmentação/organização das partes (sete performances) e dinâmicas (sete performances). A partir destes resultados, podese afirmar que a maior parte dos estudantes estava centrada no entendimento dos aspectos estruturais da partitura, e mesmo assim, não obtiveram muito sucesso nesta realização, visto que apenas quatro participantes (M4, PG10, PG11, PG12) realizaram suas performances com fluência.

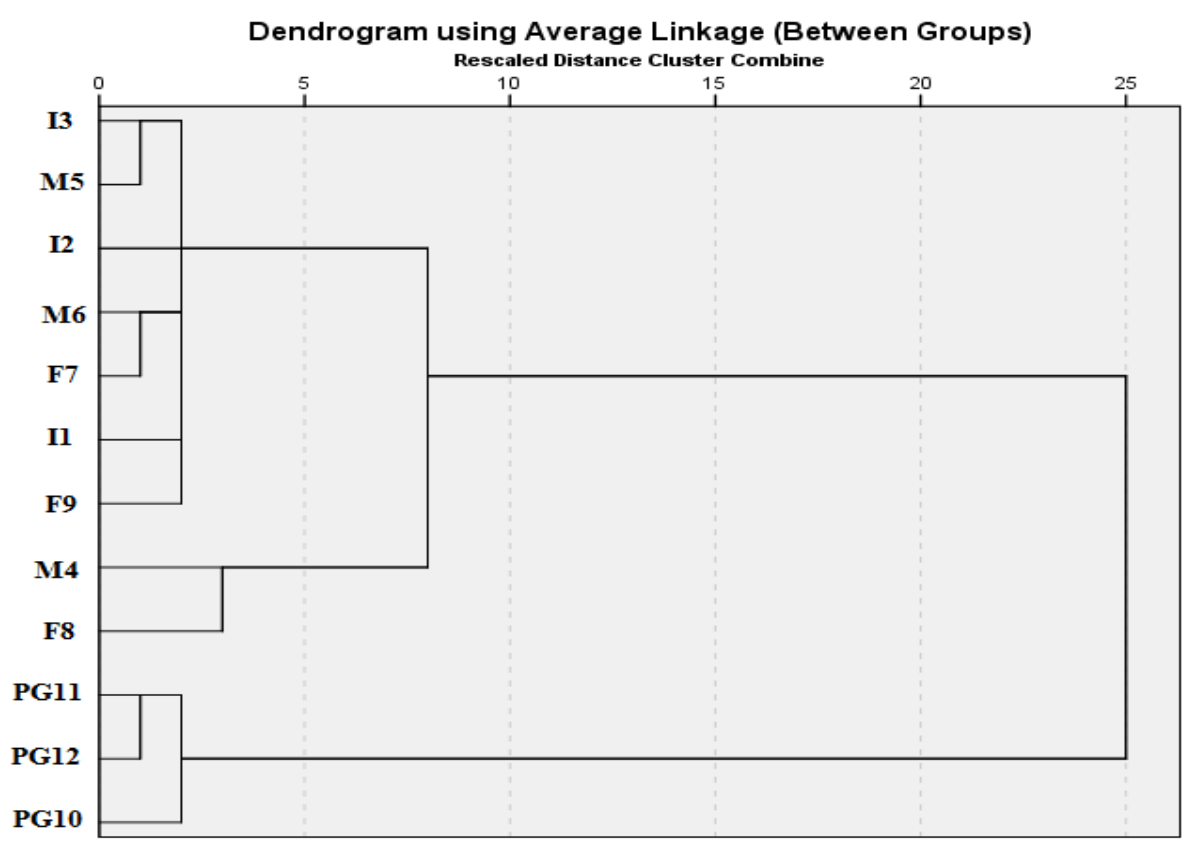

Figura 12: Dendrograma dos casos na condição B. Avaliação da performance. $\mathrm{N}=12$.

Nas performances da condição $\mathrm{C}$ os resultados foram bastante diversificados: quatro participantes (I1, M5, F7 e PG11) desistiram da tarefa, não realizando-a por completo. Em termos de fluência na execução musical, apenas dois pianistas (M4 e PG12) tocaram sem interrupções, os demais não tocaram com fluência e se perderam nas próprias anotações e/ou tiveram lapsos e memória. Além disso, oito participantes tocaram com suas anotações e quatro tocaram de memória, sendo que um estudante (F9) também fez anotação, mas preferiu tocar sem as mesmas. O dendrograma a seguir, Figura 13, apresenta a análise de clusters para esta condição, onde pode-se perceber dois agrupamentos: (i) nove participantes reunidos em dois amplos subgrupos e (ii) três participantes que desistiram da tarefa (M5, F7 e I1). 


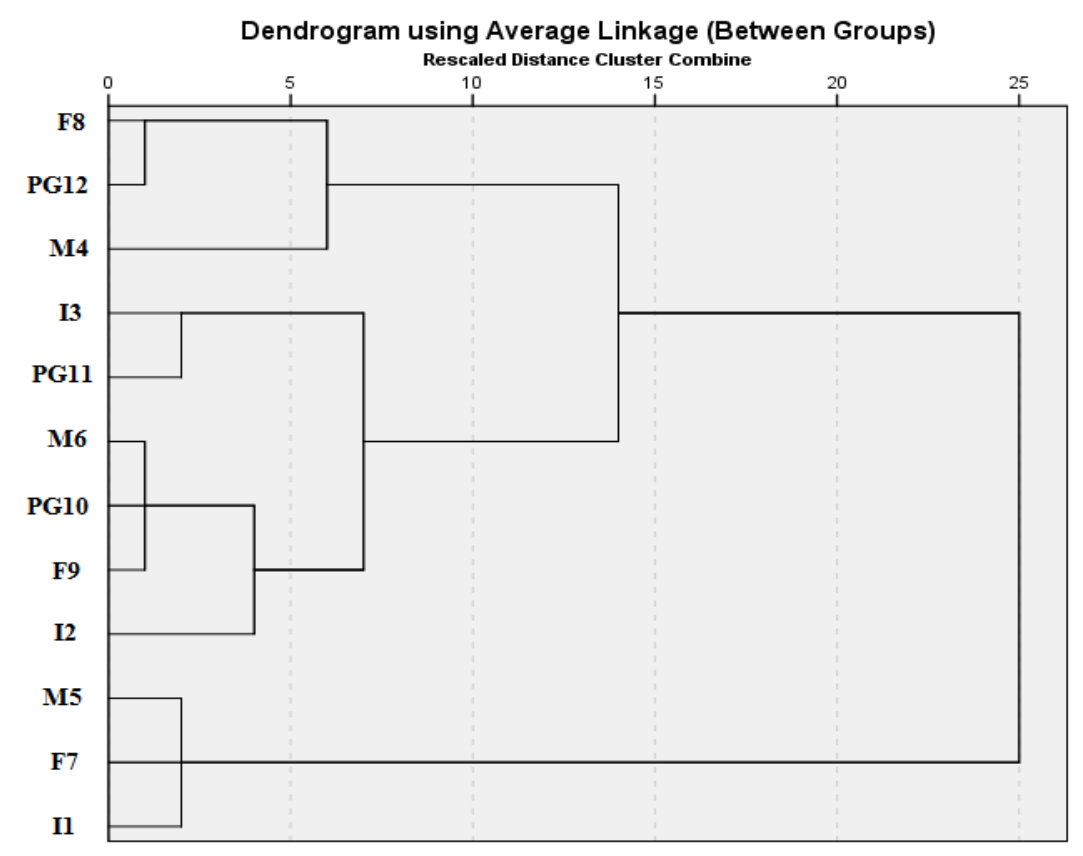

Figura 13: Dendrograma dos casos na condição C. Avaliação da performance. $N=12$.

Com relação à condição C, a análise de cluster (Figura13) permitiu classificar os estudantes em grupos totalmente desvinculados ao nível acadêmico. A partir destes resultados, constatou-se que os aspectos rítmicos, melódicos e harmônicos, assim como a segmentação/organização das partes, dinâmicas, articulações e pedal foram prejudicados durante a performance pela condição de estudo com privação da retroalimentação visual da partitura. Dentre os aspectos afetados em maior incidência estão os parâmetros melódicos/rítmicos/harmônicos (7 performances), a segmentação/organização das partes (9 performances), e dinâmicas (9 performances). Além disso, os estímulos em áudio exerceram forte influência na escolha do andamento, visto que 11 performances foram realizadas em andamentos similares e/ou próximos aos andamentos destes estímulos. Em alguns momentos, também se observou a execução de articulações (cinco performances), dinâmicas (três performances) e ornamentações (12 performances) de forma semelhante àquelas da gravação.

As performances da condição D foram bastante limitadas: três estudantes (M5, M6, F7) desistiram da tarefa e não conseguiram atingir nem mesmo um resultado parcial; três estudantes (I1, F9, PG11) também desistiram, porém conseguiram algum produto, mas ainda pouco suficiente; três estudantes (I2, I3, F8) alcançaram um resultado parcialmente satisfatório, tocando a peça por completo ou apenas a primeira parte; dois estudantes (M4 e PG10) atingiram um resultado 
satisfatório, conseguiram tocar a peça por completo; apenas um estudante (PG12) realizou a tarefa em uma margem de acertos e qualidade artística excepcionalmente diferente dos demais.

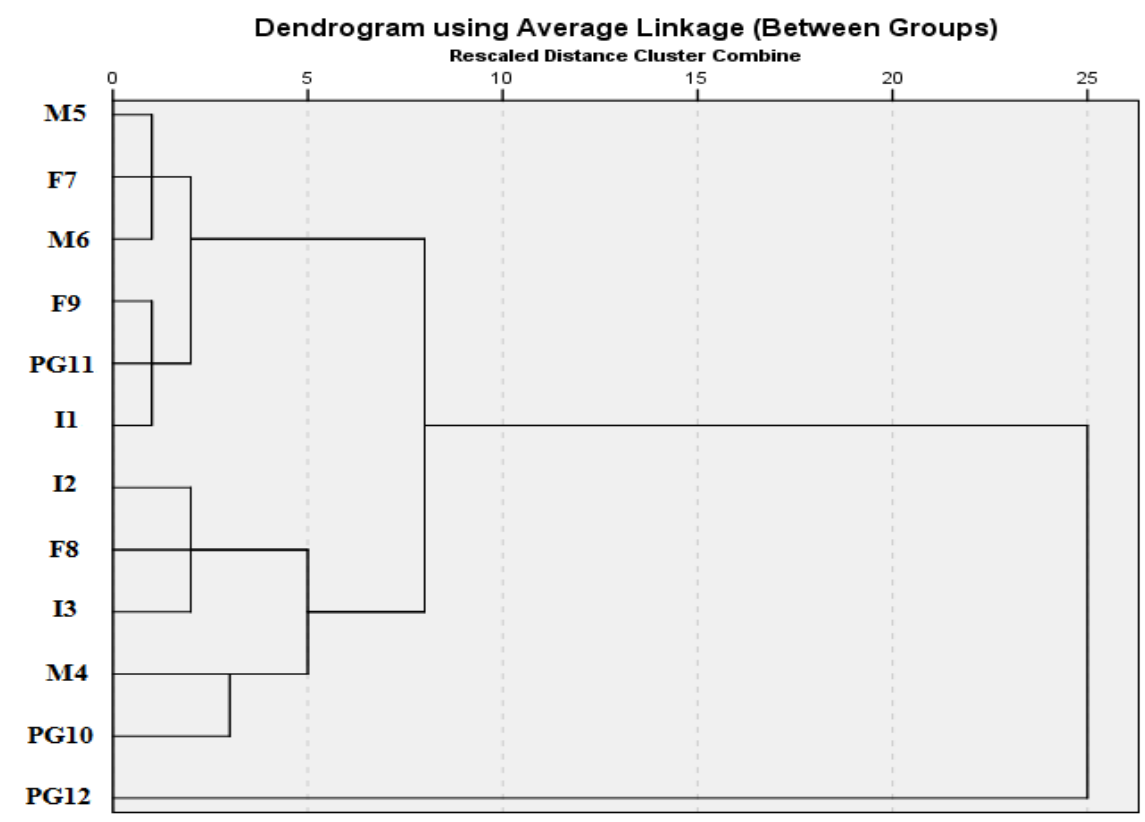

Figura 14: Dendrograma dos casos na condição D. Avaliação da performance. $\mathrm{N}=12$.

De acordo com o dendrograma resultante (Figura 14) percebe-se que onze participantes encontram-se reunidos em dois grupos, restando um participante (PG12) separado. Considerando os dois agrupamentos, observa-se: (i) seis participantes agrupados em dois subgrupos de três casos cada e (ii) cinco participantes também agrupados em dois subgrupos. Em termos de privação do estímulo aural e cinestésico, constatou-se que tais privações prejudicaram significativamente a performance em todos os parâmetros aqui considerados: apenas três participantes (M4, PG10, PG12) tocaram a peça por completo com poucos e/ou mínimos erros, e mesmo assim, de forma não fluente. Além disso, pode-se considerar que os estudantes M4 e PG10 apresentam certo nível de competência, enquanto que PG12 parece ser um caso de proficiência, resultados estes que não dão total indício de efeito do nível acadêmico, mas sim de diferentes competências pessoais acumuladas ao longo de suas trajetórias de formação. Outro aspecto que pode ter influenciado nestes resultados é o fato de que os estudantes estiveram centrados especialmente na transcrição: a alternativa de PG10 pareceu surtir efeito e, talvez se esta fosse explorada pelos demais participantes os resultados poderiam ser divergentes dos resultados obtidos até então; entretanto, esta questão fica em aberto para ser averiguada em futuras pesquisas. 


\section{4 - Considerações Finais}

Para esta amostra investigada, a análise do tempo de estudo em cada condição deu-nos evidências de que o estudo com a partitura é ainda mais efetivo, visto que as condições que demandaram mais tempo de realização (C e D) lidavam com a privação da mesma e ainda apresentaram produtos menos satisfatórios, além de casos de desistência na realização das tarefas. A análise do tempo permitiu-nos ainda revelar potencial efeito do nível acadêmico nas condições $\mathrm{A}, \mathrm{C}$ e D, visto que houve uma redução na quantidade de tempo despendida à medida que o nível acadêmico aumentava. Na condição B não houve efeito do nível acadêmico sobre o tempo de realização, porém o nível acadêmico refletiu na percepção da tarefa que fora considerada difícil pelos participantes de início e meio de curso, e fácil para os alunos de fim de curso e pós-graduação.

A partir da análise das estratégias foi possível constatar que o foco de aprendizagem foi diferenciado conforme as situações de privações de retroalimentações sensoriais. Ademais, pôdese observar que os participantes buscaram compreender os elementos básicos musicais em termos de materiais melódicos, rítmicos, harmônicos, estruturais (referente às partes), como também compreender notas e ornamentos para todas as condições. Observou-se, ainda, que níveis de proficiência mais desenvolvidos (participantes de fim de curso e pós-graduação) tendem a compreender aspectos estruturais da música em agrupamentos mais amplos em situação de privação do estímulo aural (condição A) e dos estímulos aural e cinestésico (condição B).

Em relação às performances, os efeitos das privações impostas em cada condição de estudo limitaram a qualidade dos produtos atingidos para todas as situações. Pode-se constatar efeito nível acadêmico em relação extrema nas condições A e B, visto que os alunos de pós-graduação demonstraram produtos qualitativamente superiores aos demais estudantes no que concerne à fluência na execução e comunicação expressiva. Entretanto, o nível acadêmico não influenciou na qualidade das performances das condições $\mathrm{C}$ e D, o que nos dá indícios de que a realização destas tarefas parece depender mais de competências acumuladas de cada estudante do que do nível acadêmico os quais estes se inserem.

A presente pesquisa demonstrou que cada condição teve um foco de aprendizagem distinto, e que, apesar destes focos serem diferentes, eles se complementam na prática habitual. Entender os 
aspectos estruturais, coordenar movimentos, estabelecer intenções expressivas, etc., tudo isso faz parte da prática cotidiana do instrumentista, só que nestas condições se separaram, mas, são aspectos que potencialmente poderiam ser complementares. Numa única sessão de prática foi possível ver que os focos foram diferentes, e, provavelmente, por essa razão os produtos, em sua grande maioria, foram insuficientes, ou até mesmo, fracos. Uma hipótese provável seria que as habilidades envolvidas em tais condições poderiam vir a ser refinadas, na medida em que os estudantes se habituassem a tais condições.

Em outras palavras, embora as privações aqui propostas tenham limitado a qualidade dos produtos atingidos, as condições de estudos investigadas exigiram dos participantes diferentes habilidades musicais, a saber:

(i) (ao praticar a peça), tentar escutar internamente a música, sem o estímulo sonoro do instrumento (condição A);

(ii) tentar imaginar a música e também tentar idealizar uma realização possível no instrumento (condição B);

(iii) tentar tirar um minueto clássico de ouvido (condição C);

(iv) hipotetizar sobre um possível produto a partir apenas da escuta da obra, com ou sem o recurso da transcrição (condição D).

Tais habilidades, reveladas em termos de competências adquiridas ou acumuladas pelos estudantes, podem permitir uma abordagem complementar da obra a ser estudada, no contexto das práticas interpretativas.

\section{Agradecimentos}

M.R. Mantovani agradece ao CNPq pela bolsa concedida. R.A.T. Santos agradece ao CNPq pelo financiamento parcial da pesquisa (Projeto no. 472652/2012-5) 


\section{Referências}

1. AIELlO, R.; WILLIAMON, A. (2002). "Memory". In: PARNCUTT, R.; Mc PHERSON, G., (Org). The science \& psychology of music performance. New York: Oxford University Press, p.167-181.

2. ALTENMÜLLER, E.; SCHNEIDER, S. (2009). "Planning and performance". In: HALLAM, S.; CROSS, I.; THAUT, M. (Eds.). The Oxford handbook of Music Psychology. New York: Oxford University Press, p.332-343.

3. BANTON, L. (1995). "The role of visual and auditory feedback during the sight- reading of music”. Psychology of Music, n.23, p. 3-16.

4. CHAFFIN, R.: LOGAN, T.; BEGOSH, K. (2009). "Performing from memory". In: HALLAM, S.; CROSS, I.; THAUT, M. (Eds.), The Oxford Handbook of Music Psychology, New York: Oxford University Press, p.352-363.

5. FINNEY, S. (1997). “Auditory feedback and musical keyboard performance". Music Perception, n.15, p.153-174.

6. FINNEY, S.; PALMER, C. (2003). "Auditory feedback and memory for music performance: Sound evidence for an encoding effect". Memory \& Cognition, n.31, p.51-64.

7. GINSBORG, J. (2005). "Strategies for memorizing music". In: WILLIAMON, A. Musical excellence: strategies and techniques to enhance performance. Great Britain: Oxford University Press, p.123-141.

8. GRUHN, W. (2005) “Understanding musical understanding”. In: ELLIOTT, D. (Ed.), Praxial music education. New York: University Press, p 98-111.

9. HAIR, J.; BLACK, W.; BABIN, B.; ANDERSON, E.; TATHAM, R. (2009) Análise multivariada de dados, 6ed. Porto Alegre: Bookman, p.482-535.

10. HIGHBEN, Z.; PALMER, C. (2004). "Effects of auditory and motor mental practice in memorized piano performance". Bulletin of the Council for Research in Music Education. Illinois, n.159, p.1-8.

11. REPP, B. (1999). "Effects of auditory feedback deprivation on expressive piano performance". Music Perception, n.16, p.409-438.

12. WÖLLNER, C.; WILLIAMON, A. (2007). "An exploratory study of the role of performance feedback and musical imagery in piano playing". Research Studies in Music Education, n. 29, p.39-54. 
Notas sobre as autoras

Michele Rosita Mantovani é Mestre em Música (Práticas Interpretativas-Piano/2014) pela Universidade Federal do Rio Grande do Sul (UFRGS), sob a orientação de Dra. Regina Antunes Teixeira dos Santos e da Dra. Cristina Capparelli Gerling, com apoio do CNPq; bacharel em Música (Piano/2010) pela Universidade Sagrado Coração (USC), sob a supervisão do Dr. Rosa Tolón. Tem realizado recitais solos e de música de câmara, participado de masterclasses com pianistas renomados e concursos de piano no Brasil e no Chile. Atualmente é doutoranda em Música pela UFRGS (Práticas Interpretativas/Piano) com apoio da CAPES.

Regina Antunes Teixeira dos Santos, Bacharel em Música, com habilitação Piano (UFRGS), obteve o título de Maître em Educação Musical da Université Toulouse Le Mirail (Toulouse, França). Realizou aperfeiçoamento em piano com Profa. Minako Fujita (Ueno Gakkuen, Tóquio, Japão). Em 2003 concluiu dissertação de Mestrado em Educação Musical (UFRGS) e em 2007, sua tese de Doutorado em Educação Musical (UFRGS) sob orientação da Prof ${ }^{a}$. Dra. Liane Hentschke. No período 2008-2010 realizou pós-doutorado em práticas interpretativas (UFRGS), sob supervisão da Profa. Dra. Cristina Capparelli Gerling. De 2011 a 2012 foi professora de teclado da FUNDARTE. Atualmente é professora do Instituto de Artes da UFRGS. Em pesquisa, sua área de atuação concentra-se na interconexão entre performance instrumental, conhecimento musical e estratégias de expressão emocional. 